\title{
Neuronal c-Fos Reactivity of Medial Prefrontal Cortex and Basolateral Amygdala in Perinatally Underfed Lactating Wistar Rats
}

\author{
Manuel Salas ${ }^{\circledR}$, Minerva Ortiz-Valladares, Mirelta Regalado, Carmen Torrero \\ Department of Developmental Neurobiology and Neurophysiology, Institute of Neurobiology, National Autonomous University \\ of Mexico, Queretaro, Mexico \\ Email:masal@unam.mx
}

How to cite this paper: Salas, M., Ortiz-Valladares, M., Regalado, $\mathrm{M}$ and Torrero, C. (2020) Neuronal c-Fos Reactivity of Medial Prefrontal Cortex and Basolateral Amygdala in Perinatally Underfed Lactating Wistar Rats. Journal of Behavioral and Brain Science, 10, 548-561.

https://doi.org/10.4236/jbbs.2020.1012034

Received: October 27, 2020

Accepted: December 8, 2020

Published: December 11, 2020

Copyright $\odot 2020$ by author(s) and Scientific Research Publishing Inc. This work is licensed under the Creative Commons Attribution International License (CC BY 4.0).

http://creativecommons.org/licenses/by/4.0/

\begin{abstract}
Pre- and neonatal food restriction interferes with the neuronal and functional organization of long-term social adaptive responses including the maternal response to ensure pup survival. We addressed this issue by using low percentages of food from gestational days G6 to G 19 (50\% to 30\%) followed by a balanced diet from G20 to G21. After birth, pups were underfed by rotating two lactating dams, one with tied nipples, every $12 \mathrm{~h}$. Weaning was at 25 days of age and thereafter an ad libitum diet. The F1 dams' motivation (pup retrieval, handling shavings and crouching) was evaluated (10 min) at 4 and 12 days of lactation, when they had reached 90 days of age. The maternal neuronal functionality was measured by immunostaining the medial prefrontal cortex and the basolateral amygdala when the pups were removed from their dams 90 min after suckling. Underfed dams exhibited significantly lower pup retrieval, handling shavings and crouching frequencies, as well as prolonged latencies for pup retrieval and for handling shavings and crouching. Furthermore, early underfed dams had Fos-I neuron deficiencies mainly in the prefrontal cortex, with minor effects on the amygdala, possibly because the pups' cues to elicit maternal motivation were suboptimal and/or because of the deficient network activation.
\end{abstract}

\section{Keywords}

Early Undernutrition, Lactating Dams, Fos-I Alterations, Rats

\section{Introduction}

In altricial species, maternal care is an innate basic response necessary for the growth and survival of the progeny that requires precise and specific morpho- 
functional neuronal changes mediated by hormone fluctuations and the impact of multisensory environmental cues [1] [2] [3] [4]. Because rats are immature at birth, they strongly depend on parental attentiveness to surpass environmental demands such as surrounding temperature variations, excreta elimination, feeding, maternal attachment, and body licking, among others [5] [6] [7] [8]. Furthermore, strong mother-litter bonds in the postpartum period may determine behavioral, cognitive, and intellectual capacities in adulthood [9] [10] [11].

Several studies have suggested that early undernutrition and sensory environmental deficiencies are newborn risk factors that may interfere with structures underlying maternal behavior, learning, and electrophysiological responses by decreasing neurogenesis and disrupting the transmission and possibly encoding of signals and their integration from subcortical levels to the cerebral cortex [12]-[17]. Furthermore, pre- and neonatal malnutrition of F0 underfed lactating dams results in long-term F1 maternal deficiencies, including pup retrieval, licking, nursing and nest building responses, which are associated with neuronal alterations in the cortical and limbic networks underlying maternal responsiveness [15] [18] [19] [20]. Thus, the medial prefrontal cortex (mPFC) is involved in the generation of motivation, attention and the modulatory effects of sensory signals associated with maternal care and is disrupted by lesions and noxious environmental manipulations [21] [22] [23] [24]. By contrast, the amygdala has been linked to the activation or inhibition of the maternal response, and its lesion facilitates the maternal response by interfering with the modulatory olfactory bulb activity [25]. Moreover, medial amygdala stimulation suppresses the appearance of the maternal components [26] [27], and excitotoxic lesions of this area in virgin females release the maternal responsiveness by interfering with projections to the anterior/ventromedial hypothalamic nuclei that inhibit maternal response [28]. Additionally, the basolateral amygdala (BLA) has a central role in memory consolidation and provides pup-related sensory inputs to several brain areas for the activation of the mesolimbic system that possibly potentiates the ability of BLA neurons to stimulate goal-directed maternal responses [29] [30] [31] [32]. Studies of our group have shown that perinatal undernutrition in the lactating rat was associated with specific morphological and perhaps different excitability changes in the neuronal perikarya and dendritic arbor organization of multipolar and pyramidal mPFC and BLA neurons, which are functionally poorly understood in the regulation of the mother litter bonds and their disorders [15].

The aim of this study was to analyze the motivational long-term effects on some maternal components at two lactating days, and if the immediate early-gene product Fos-I, used as a marker for neuronal activation, could be differentially affected in the MPFC and BLA neurons of perinatally underfed dams.

\section{Material and Methods}

\subsection{Animals}

Subjects were adult F0 female Wistar rats $(200$ - 300 g) and their F1 offspring 
originally obtained from a Harlan Sprague-Dawley (IN-USA) stock. The subjects were housed at the Institute of Neurobiology of the National Autonomous University of Mexico and kept in a room with a temperature of $24^{\circ} \mathrm{C} \pm 2^{\circ} \mathrm{C}$, humidity of 50\%, a light/dark cycle of 12/12h (lights on at 08:00 h), and food (Purina chow) and water ad libitum. For mating, two males were placed in a plastic cage $\left(60 \times 50 \times 20 \mathrm{~cm}^{3}\right)$ containing four virgin females. Sperm-positive females were individually housed in plastic maternity cages $\left(50 \times 40 \times 20 \mathrm{~cm}^{3}\right)$ with wood shavings as nesting material one week prior to parturition. The pups were weighed and sexed the day after birth. The litter was adjusted to five males and five females to minimize genetic and nutritional differences that could influence the experimental results. The protocols and animal care were approved by the Local Animal committees project 108.A, the Official Mexican Standard NOM-062-Z00-1999 that were in accordance with the guidelines for the Care and Use of Animals in Neuroscience and Behavioral Research, [33].

\subsection{Nutritional Treatments}

\subsubsection{Control Group (CG)}

The CG group consisted of 10 females obtained from ten different normally fed subjects, nursed by well-fed mothers with free access to food and water. The subjects ( $\mathrm{cF} 0)$ were maintained with free access to food (5001 rodent Purina chow) and water during the gestational and lactating periods. After birth, the CG pups were nourished by rotating a pair of normally lactating F1 dams (one with a sham nipple ligature) every $12 \mathrm{~h}$ for 24 days as previously described [34]. After weaning on postnatal day (PD) 25 , the subjects had free access to water and solid food. The female rats obtained by this method were mated and maternally tested as adults on PD 90. Their brains were subsequently processed for c-Fos immunohistochemistry.

\subsubsection{Undernutrition Group (UG)}

This group consisted of 10 female ( $\mathrm{uF} 0$ ) rats mated overnight. The day of the vaginal sperm-positive smear was designated as gestational day 0 (G0). The standard chow diet requirement was calculated by measuring the food intake of a group of six pregnant control dams (200 - $250 \mathrm{~g})$ every week during a 21 -day period; the nutritional requirement during gestation was $143 \mathrm{kcal} / \mathrm{BWkg}$ in early gestation and $265 \mathrm{kcal} / \mathrm{BWkg}$ in later gestation [35]. The resulting average food intake per week was the basal level used to calculate the food intake percentage of the UG F0 dams. Thus, dams were fed with 50\% (9.5 g) of the normal diet from G6 to G12, with 70\% (13.3 g) from G13 to G19 and with $100 \%$ (19 g) of the same diet until parturition to avoid cannibalism of pups [20]. The protocol was designated because neurogenesis of the cortical and limbic structures related to maternal circuitry occurs mainly from G16 to G21 [36]. At birth, prenatally underfed $\mathrm{uF} 1$ pups were nursed by two gestationally underfed dams, in one of which the main galactophorous ducts had been subcutaneously tied [34]. These two lactating dams were gently interchanged (30 
sec) every $12 \mathrm{~h}$ between litters from PDs 1 to 24 . Weaning occurred at PD 25, followed by a balanced diet until PD 90 when the dams were maternally tested (Figure 1). Body weight was recorded to evaluate the physical conditions of the F0 dams between G0 and postpartum day 1 . The reactivity of c-Fos protein in the MPFC and BLA areas was analyzed by immunohistochemistry of the same rats used in the behavioral testing of the current study, Dams were sacrificed on different lactating days.

\subsection{Behavioral Testing}

For maternal response evaluation, we used 10 CG and 10 UG dams that were assessed in their home cage at PD 90. Three days prior to parturition, the dams were placed in translucent plastic maternity cages $\left(20 \times 40 \times 60 \mathrm{~cm}^{3}\right)$ with wood shavings as bedding. Twenty-four hours after parturition, each litter was culled to 10 pups ( 5 males and 5 females). Initially, each mother received two retrieval tests with her own litter on lactating days (LD) 4 and 12, between 10:00 and 12:00 $\mathrm{h}$, when the maternal response was highly expressed [37]. Maternal behavior components included the frequency and latency of the following measurements: pup retrieval, number of times the dam retrieves the first pup in the litter by a particular body area; handling shavings that energizes the lactating dam to make a shelter for the care of pups [38], attempts to move wood shavings to build or maintain a nest; and crouching, number of times the dam maintains a quiescent posture with a partially arched back and most of the limbs extended over the pups to promote nursing. These maternal components were highly expressed at LD 4 and gradually declined at LD 12 according to two different maternal motivational stages [39] [40]. The responses were videotaped (10 $\mathrm{min})$ in a sound-proof chamber under continuous dim illumination provided by a red lamp (100 W = $130 \mathrm{~cd}$, Philips Co. Amsterdam, Netherlands).

\section{4. c-Fos Immunoreactivity}

c-Fos is a class of immediate-early genes expressed in response to various stimulus conditions [41]. c-Fos has been shown to be expressed in a variety of neurons responding to sensory, hormonal, neurochemical and behavioral events such as maternal behavior, which implicates all the mentioned components.

Ninety minutes after the mother exhibited the kyphotic postures, ten lactating dams divided into the two nutritional regimes $(n=5$, undernourished, $n=5$, control), were anesthetized with $150 \mathrm{mg} / \mathrm{kg}$ sodium pentobarbital (Cheminova, Mexico) and perfused through the heart with $150 \mathrm{ml}$ of $0.9 \%$ saline followed by $150 \mathrm{ml}$ of $4 \%$ paraformaldehyde (Sigma, USA) dissolved in $0.1 \mathrm{M}$ sodium phosphate buffered saline (PBS, $\mathrm{pH}$ 7.4). Brains were removed and post-fixed overnight in $4 \%$ paraformaldehyde and after in $30 \%$ sucrose in $0.1 \mathrm{M} \mathrm{PBS}(\mathrm{pH} 7.4)$ for 4 weeks before sectioning. We sectioned the brains in coronal segments of 40 $\mu \mathrm{m}$ and immunocytochemically processed them for c-Fos-IR in free-floating sections. 
A) Underfeed procedure

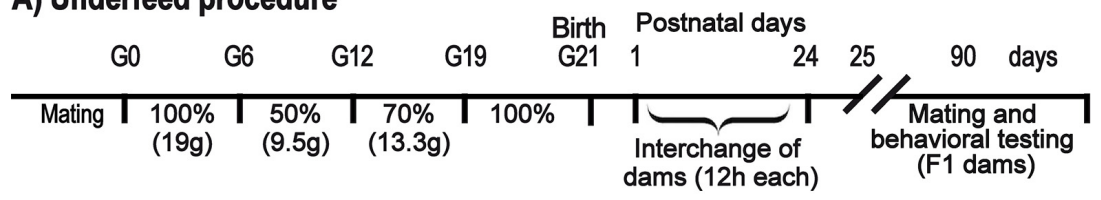

B) Behavioral testing (F1 dams)

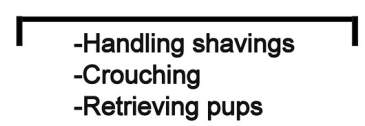

\section{C) C-Fos immunoreactivity}

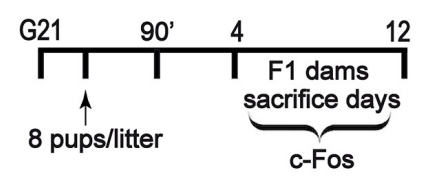

Figure 1. Experimental design for (A) underfeed procedure, (B) Behavioral testing and (C) c-Fos immunoreactivity.

\section{Quantitative Analysis of Fos Activity}

c-Fos immunostaining was evaluated between the appearance of the maternal components and the initiation of suckling of pups in different brain areas of CG and UG dams during a 10 min span at LDs 4 and 12, without previous mother-litter separation. Ninety minutes after mother-litter interactions, the dams were sacrificed under deep sodium pentobarbital anesthesia $(150 \mathrm{mg} / \mathrm{kg})$. The brains were removed, frozen and cut into $40-\mu \mathrm{m}$ thick coronal sections using a vibratome and then stored until processing.

The immunohistochemistry assay initiated with washed tissue with hydrogen peroxide 3\% for $10 \mathrm{~min}$. The tissue section was incubated with polyclonal antiserum raised against the $\mathrm{N}$-terminal fragment of human Fos protein (Santa Cruz Biotechnologies CA, USA) diluted 1:1000 into PBS 1\% Triton X-100 with $100 \mu \mathrm{l}$ of normal goat serum solution at $4^{\circ} \mathrm{C}$ for $48 \mathrm{~h}$. The sections were washed and incubated with biotinylated goat anti-rabbit secondary antiserum (Vector Labs Inc. Burlingame, CA) diluted 1:400 with PBS 1\% at room temperature for $2 \mathrm{~h}$ and processed using the standard biotin avidin-peroxidase kit (Vectastain Labs Inc. Burlingame, CA) for $90 \mathrm{~min}$ at room temperature. Tissues were sliced and reacted with nickel chloride 3-3' diaminobenzidine and $0.06 \%$ hydrogen peroxide (DAB kit Labs Inc. Burlingame, CA). To finish, sections were washed, mounted onto gelatin-coated slides previously dehydrated with alcohols in different densities, and cover slipped.

To measure the immunoreactivity of c-Fos protein, we took six random tissue samples per structure on each diet and lactation day. We distinguished between both hemispheres to identify possible lateralization effects. For mPFC, the tissue was sampled between +3.20 and +1.70 of Bregma and neurons were taken from layer III. For the BLA nucleus, the neurons were obtained between -2.30 and -3.30 of Bregma [42]. The mPFC were positioned into a $200 \times 600 \mu \mathrm{m}$ rectangle and for BLA were positioned into a $200 \times 200 \mu \mathrm{m}$ squares, and we considerate round intense c-Fos-IR nuclei laying fully within rectangle or square according with each structure. Sections were measured with a Leica DM7500 light microscope at a magnification of $10 \mathrm{X}$. 


\subsection{Statistics}

To compare differences in dietary treatments, ages, body weights of dams, handling shavings, pup retrieval, and crouching, the following separate statistical analyses were used. 1) The body weight differences of dams on G0 vs. postpartum day 1 were compared with a two-way ANOVA, 2 (nutritional regimes) $\times 2$ (lactating days). 2) The frequency, latency and duration of handling shavings, retrieval of pups and crouching of dams were measured with a two-way ANOVA, 2 (nutritional regimes) $\times 2$ (lactating days). Immunocytochemical results were analyzed with a two-way ANOVA, 2 (nutritional regimes) $\times 2$ (lactating days). The post hoc statistical comparisons between experimental groups were compared using the Fisher LSD post hoc test. In all cases, the alpha level was set at $\mathrm{p}$ $<0.05$.

\section{Results}

\subsection{Effects on Body Weight of Dams}

\section{Perinatal Undernutrition Disrupted Body Weight Gain of Lactating} Dams

The ANOVA comparisons of body weight scores between G0 and LD 1 showed low body weight in the uF1 dams $\left(\mathrm{F}_{1,38}=382.39, \mathrm{p}<0.0001\right.$, and interaction diet by age $\left(\mathrm{F}_{1,38}=8.60, \mathrm{p}<0.005\right)$.

\subsection{Effects on the Maternal Responses}

Perinatal Food Restriction Disrupted Maternal Behavioral Performance The UG ANOVA comparisons showed significant reductions in the frequency of handling shavings combined with crouching of dams $\left(\mathrm{F}_{1,36}=12.73, \mathrm{p}<0.001\right)$, without effects of age, and the interaction between factors. Furthermore, significant prolonged latency of accumulated handling shavings plus crouching scores in the UG $\left(\mathrm{F}_{1,36}=17.42, \mathrm{p}<0.0001\right)$, effects of age $\left(\mathrm{F}_{1,36}=4.43, \mathrm{p}<0.04\right)$, and no interaction between factors were also obtained. Post hoc comparisons between groups at different lactation days indicated significant reductions $(p<0.05)$ in the frequency of handling shavings and crouching at LDs 4 and 12, and the total accumulated days effect (Figure 2(A)).

Moreover, significant $(\mathrm{p}<0.05)$ prolonged latencies of these same components at LDs 4 and 12 and the total accumulated scores (Figure 2(B)) were also observed. Comparisons between the frequency of pup retrieval by UG dams showed significantly lower values $\left(\mathrm{F}_{1,36}=15.27 \mathrm{p}<0.0003\right)$; no effects of age but significant interaction diet by age $\left(\mathrm{F}_{1,36}=4.37 \mathrm{p}<0.04\right)$. Post hoc comparisons between groups showed significant $(\mathrm{p}<0.05)$ reductions in the frequency of retrieval only at LD 12 and in the total accumulated LDs (Figure 2(C)). The ANOVA comparisons between the latency of pup retrieval by UG dams showed significant prolonged values $\left(\mathrm{F}_{1,36}=31.26, \mathrm{p}<0.0002\right)$; effects of age $\left(\mathrm{F}_{1,36}=\right.$ $25.83, \mathrm{p}<0.0001)$, and a significant interaction diet by age $\left(\mathrm{F}_{1,36}=6.69, \mathrm{p}<0.01\right)$. Post hoc analysis showed significant $(\mathrm{p}<0.05)$ prolonged latencies at LDs 4 and 12 and in the total accumulated days of lactation (Figure 2(D)). 
A

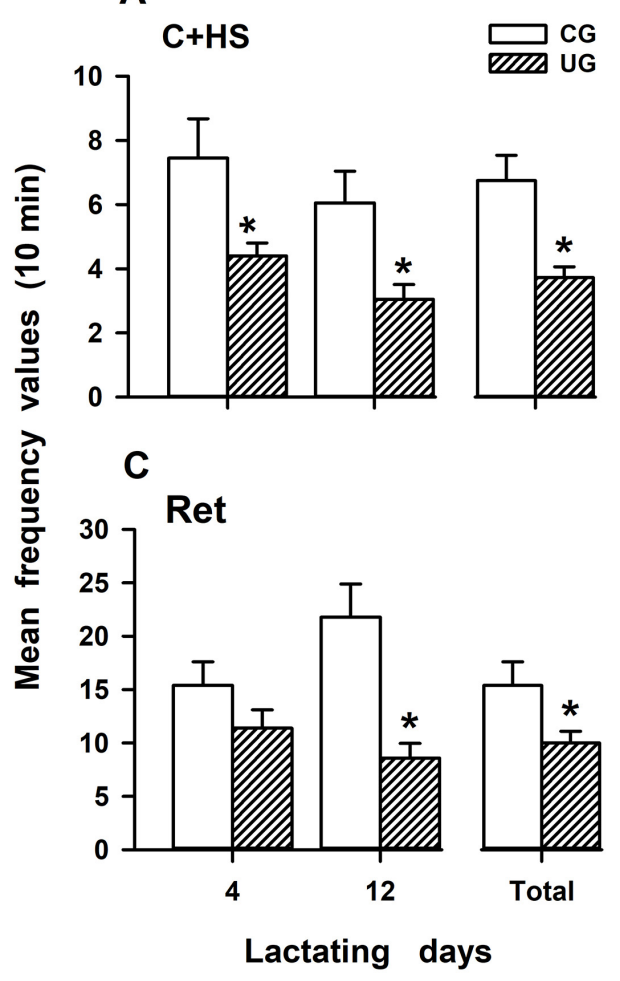

B $\mathrm{C}+\mathrm{HS}$

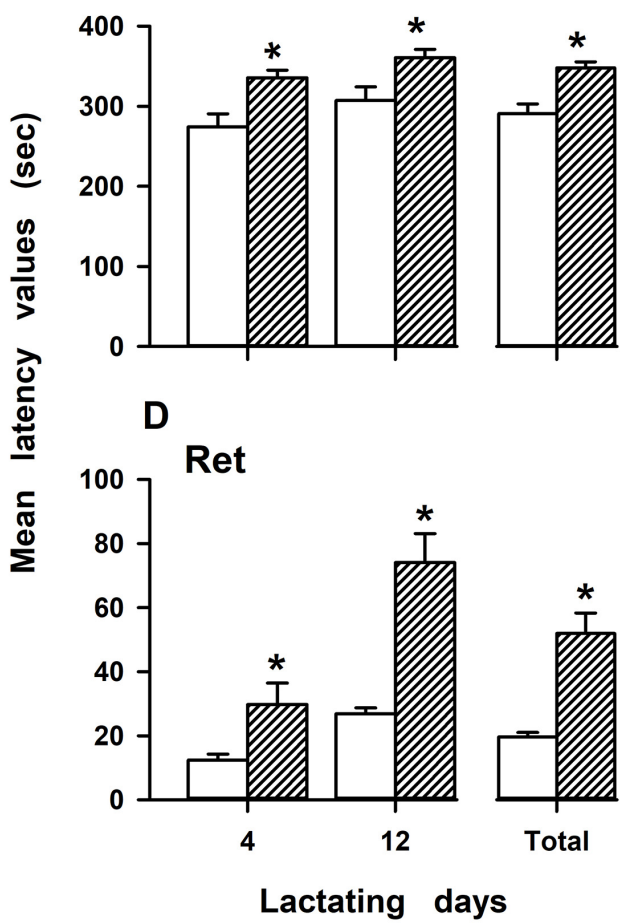

Figure 2. Mean values \pm SEM for the (A) frequency and (B) latencies of crouching plus handling shavings (C + HS); (C) retrieving (Ret) frequency and (D) latencies for retrieving (Ret) of CG and UG dams at LDs 4 and 12 . Note that the frequency of responses was significantly reduced, and latencies prolonged in the UG dams. ${ }^{*}$ Post hoc comparisons on the lactating days showed significant differences between groups, $\mathrm{p}<0.05$, Fisher LSD test.

\subsection{Effects on the c-Fos Immunorectivity}

\section{Neuronal c-Fos Immunoreactivity Is Affected in Underfed Lactating Dams}

The counts of the right and left mPFC were combined because no statistical differences were observed between them. Thus, the ANOVA comparisons of c-Fos protein, activated within the $\mathrm{mPFC}$ after the maternal response, showed significantly reduced c-Fos immunolabeling in UG F1 dams $\left(\mathrm{F}_{1,116}=59.71, \mathrm{p}<0.0001\right)$; reduction effects by age $\left(\mathrm{F}_{1,116}=5.53, \mathrm{p}<0.020\right)$, and no interaction between factors. Post hoc comparisons indicated that UG dams significantly $(\mathrm{p}<0.05)$ diminished c-Fos immunolabeling after maternal response exposure on LDs 4 and 12 and in the total accumulated days of lactation (Figure 3(A)).

The ANOVA comparisons of $\mathrm{c}$-Fos protein, elicited within the BLA neurons following the maternal responsiveness indicated significant attenuated c-Fos immunolabeling in the UG F1 mothers $\left(\mathrm{F}_{1,116}=14.56, \mathrm{p}<0.0002\right)$; effects of age $\left(\mathrm{F}_{1,116}=8.71, \mathrm{p}<0.003\right)$ and significant interaction between diet by age $\left(\mathrm{F}_{1,116}=\right.$ 45.56, $\mathrm{p}<0.0001)$. Post hoc comparisons showed that UG dams significantly reduced $(\mathrm{p}<0.05) \mathrm{c}-$ Fos immunolabeling after the maternal response on LD 4 , with significant $(\mathrm{p}<0.05)$ opposite effects on LD 12 and significant $(\mathrm{p}<0.05)$ reductions in the total accumulated days of lactation (Figure 3(B)). 


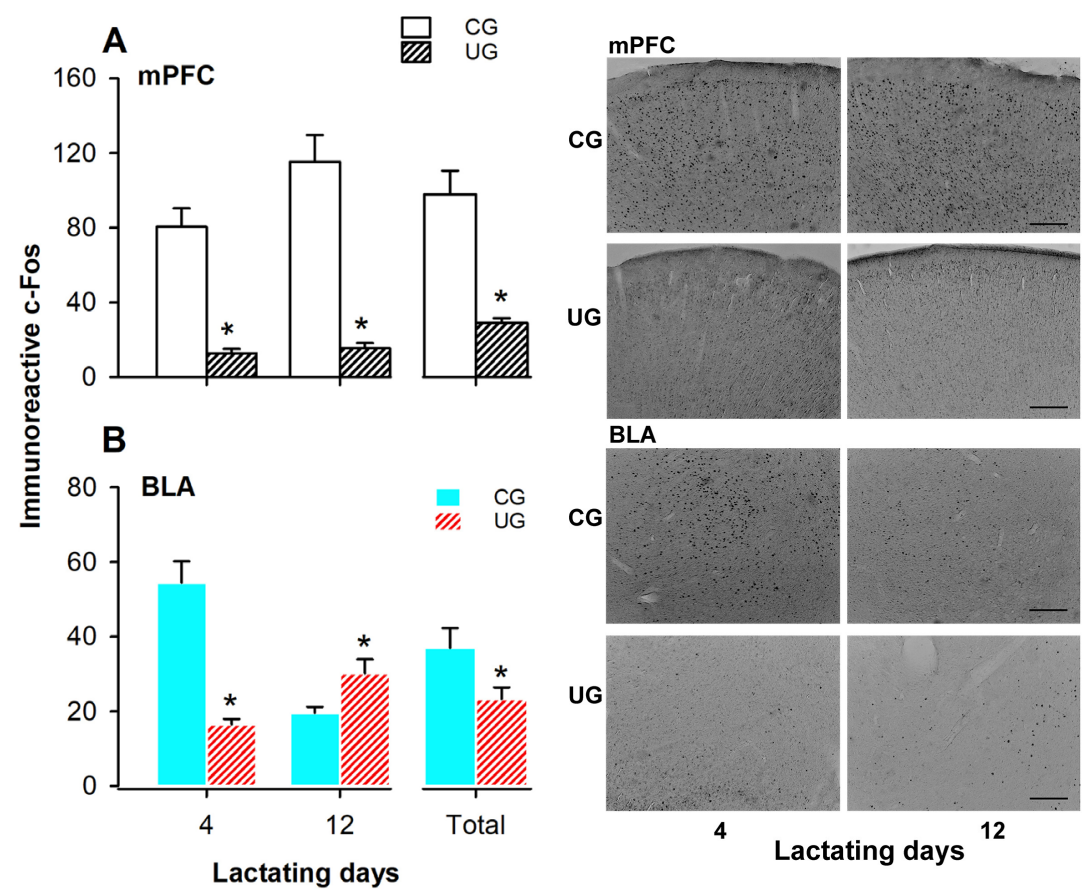

Figure 3. Bilateral density of c-Fos immunolabeling at the (A) MPFC and (B) BLA on LDs 4,12 and total comparison. ${ }^{*} \mathrm{p}<0.05$. (Right) photomicrographs of Fos-IR of representative $\mathrm{mPFC}$ and BLA of CG and UG groups at LDs 4 and 12 at a magnification of 10X. Scale bar, $200 \mu \mathrm{m}$. Note the reduction in the labeling of UG dams in the comparisons following the pups' exposure.

\section{Discussion}

Our findings indicate that pre- and neonatal undernutrition induced significant reductions in the body weight of F1 dams between G0 and LD 1 at 90 days of age when they were on a balanced diet and tested for maternal behavior. The prenatal underfeeding procedure established in F0 dams included 50\% to 30\% of food restriction (G6 to G20), which possibly interfered with the placenta size, its weight and fetal nutrition as described elsewhere [43] [44]. F1 pups from PDs 1 to 24 were underfed by rotating two lactating rats, one with tied nipples, between litters, resulting in relevant sensory deficiencies in the mother-litter interactions and long-term behavioral consequences [20] [45]. Our underfeeding paradigm thus provides a unique model to evaluate disrupted high or low maternal motivational levels during the lactation period. Thus, in further studies current model may be challenged by the exposure to noxious, novel cues or addictive drugs [40] [46].

Furthermore, present results indicate that early underfed F1 lactating dams exhibited significantly lower motivational motoric activity that urges the dam to nurture their young as reflected in reduced frequencies for handling shavings, crouching, and retrieving pups for grouping, as well as prolonged latencies to accomplish these maternal components. The responses maintained a consistent expression at LDs 4 and 12 in both experimental groups; however, UG females showed reduced maternal care compared with CG dams mainly at LD 12, possi- 
bly reflecting diminished maternal motivational levels [47]. Furthermore, because pre- and neonatal undernutrition provoked diffuse and neuronal damages of the dendritic arbor, spine density, and perikarya measurements at different cortical and subcortical structures underlying the maternal responses including the mPFC and BLA neurons [15] [24] [48] [49]. In this regard, our results could be related to the maternal motivational disruptions (i.e., retrieval and nest-building responses) in lactating dams caused by bilateral excitotoxic lesions to the medial preoptic area (MPOA) and the bed nucleus of the stria terminalis [28] [50]. Another point of interest concerns to the role of the stress sensitivity of the UG dams associated with maternal separation to provoke motivational deficiencies ameliorated by the dam rotation procedure, and a brief (1-2 min) mother-litter separation that does not consistently affect maternal responsiveness [39]. Thus, the maternal deficiencies in the UG dams may primarily be related to the gestational food restriction, as previously reported for other types of stress depending of social cognitive responses [45] [51]. However, further studies may be necessary to discard a possible effect of perinatal stress on the lactating UG dams. Additionally, perinatal food restriction procedures affect the cytoarchitectonic sensory organization and motoric functional brain development including the complex motivational aspects of the maternal response. During the lactation period, the dams' motivation is strongly influenced by the pups' sensory cues. Hence, present maternal deficiencies in the maternal motivation could be related to deficient odor, sound and visuospatial discriminations of the pups and/or dams and other environmental signals as described in studies with perinatal food and sensory deprived dams [11] [52] [53] [54].

Current findings also indicate that UG F1 lactating dams have high deficiencies in c-Fos immunolabeling at LDs 4 and 12, mainly in the MPFC, with minor effects on the neuronal activity of the BLA. These findings may be related to the interference of sensory integration in UG dams because the reduced somatosensory cues from the pups, which elicit maternal motivation for crouching, were suboptimal and/or because of a possible deficient threshold of nursing network activation [11] [55]. Additionally, similar studies indicated that UG dams have severe deficiencies in their maternal behavioral performance, although they are able to learn poorly and improve the care of the pups after the exposure to chronic handling, an enriched sensory environment or through the experience obtained from successive parturitions, which is consistent with the present c-Fos-IR findings [53] [56] [57]. Furthermore, the BLA may play a role in maternal memory consolidation and provides pup-related sensory inputs to several maternal brain areas for the activation of the mesolimbic system, which potentiates the ability of BLA neurons to stimulate goal-directed maternal responses [29] [30] [31] [32]. Present results suggest that the neuronal plasticity of the $\mathrm{mPFC}$ and BLA, as parts of the limbic network underlying maternal motivation, is differentially affected by early undernutrition (Figure 3). Although in our UG lactating dams motivation for caring their own pups is clearly interfered, how- 
ever current findings may have several limitations to explain for instance, how UG dams will respond when feeding healthy newborns, how the UG maternal motivation changes by chronic fresh pups exposure, at different lactating days, following repeated parturitions or competing with addictive drugs. Furthermore, the use of morphometric and immunostaining markers at different motivational relays would be of interest for future studies in this early underfeeding research line. These findings may be useful to understand possible clinical deficiencies that affect learning in dams and the care of the progeny.

\section{Conclusion}

Current maternal behavioral responses of early UG lactating dams reflected the long-term interference with the neuronal integrative processes underlying the care and survival of the newborns. Furthermore, early underfed dams have deficiencies of Fos-I neurons, mainly in the mPFC and with minor effects on BLA activity, possibly because the pups' cues to elicit maternal motivation were suboptimal and/or because of the deficient nursing network activation. Our findings suggest that the maternal circuitry plasticity of UG dams during the pre- and neonatal stages was insufficient for the integration of cognitive processes such as maternal motivation for the care of the progeny.

\section{Acknowledgements}

This work was partly supported by DGAPA/UNAM, IN200317. We thank Jessica Gonzalez Norris for editorial assistance and helpful suggestions, and CONACYT scholarship 660096 to MOV.

\section{Conflicts of Interest}

The authors declare no conflicts of interest regarding the publication of this paper.

\section{References}

[1] Rosenblatt, J.S., Mayer, A.D. and Giordano, A.L. (1988) Hormonal Basis during Pregnancy for the Onset of Maternal Behavior in the Rat. Psychoneuroendocrinology, 13, 29-46. https://doi.org/https://doi.org/10.1016/0306-4530(88)90005-4

[2] Kinsley, H.C. and Lambert, K.G. (2006) The Maternal Brain. Scientific American, 294, $72-79$.

[3] Febo, M., Stolberg, T.L., Numan, M., Bridges, R.S., Kulkarni, P. and Ferris, C.F. (2008) Nursing Stimulation Is More than Tactile Sensation: It Is a Multisensory Experience. Hormones and Behavior, 54, 330-339. https://doi.org/10.1016/j.yhbeh.2008.02.024

[4] Bridges, R.S. (2015) Neuroendocrine Regulation of Maternal Behavior. Frontiers in Neuroendocrinology, 36, 178-196. https://doi.org/10.1016/j.yfrne.2014.11.007

[5] Teicher, M.H. and Blass, E.M. (1977) First Suckling Response of the Newborn Albino Rat: The Roles of Olfaction and Amniotic Fluid. Science, 198, 635-636. https://doi.org/10.1126/science.918660 
[6] Moore, C.L. (1984) Maternal Contributions to the Development of Masculine Sexual Behavior in Laboratory Rats. Developmental Psychobiology, 17, 347-356. https://doi.org/10.1002/dev.420170403

[7] Brouette-Lahlou, I., Godinot, F. and Vernet-Maury, E. (1999) The Mother Rat's Vomeronasal Organ Is Involved in Detection of Dodecyl Propionate, the Pup's Preputial Gland Pheromone. Physiology \& Behavior, 66, 427-436. https://doi.org/10.1016/S0031-9384(98)00334-5

[8] Moriceau, S. and Sullivan, R.M. (2006) Maternal Presence Serves as a Switch between Learning Fear and Attraction in Infancy. Nature Neuroscience, 9, 1004-1006. https://doi.org/10.1038/nn1733

[9] Macrì, S. and Würbel, H. (2006) Developmental Plasticity of HPA and Fear Responses in Rats: A Critical Review of the Maternal Mediation Hypothesis. Hormones and Behavior, 50, 667-680. https://doi.org/10.1016/j.yhbeh.2006.06.015

[10] Masís-Calvo, M., Sequeira-Cordero, A., Mora-Gallegos, A. and Fornaguera-Trías, J. (2013) Behavioral and Neurochemical Characterization of Maternal Care Effects on Juvenile Spraguedawley Rats. Physiology \& Behavior, 118, 212-217. https://doi.org/10.1016/j.physbeh.2013.05.033

[11] Salcedo, C., Torrero, C., Regalado, M., Rubio, L. and Salas, M. (2018) Effects of Preand Neonatal Undernutrition on the Kyphotic Response and C-Fos Activity in the Caudal Periaqueductal Gray of Primiparous Lactating Wistar Rats. Physiology \& Behavior, 185, 87-94. https://doi.org/10.1016/j.physbeh.2017.12.020

[12] Math, F. and Davrainville, J.L. (1980) Electrophysiological Study on the Postnatal Development of Mitral Cell Activity in the Rat Olfactory Bulb. Brain Research, 190, 243-247. https://doi.org/10.1016/0006-8993(80)91174-9

[13] Stern, J.M. and Johnson, S.K. (1990) Ventral Somatosensory Determinants of Nursing Behavior in Norway Rats. I. Effects of Variations in the Quality and Quantity of Pup Stimuli. Physiology \& Behavior, 47, 93-1011. https://doi.org/10.1016/0031-9384(90)90026-Z

[14] Salas, M. and Cintra, L. (1973) Nutritional Influences upon Somatosensory Evoked Responses during Development in the Rat. Physiology \& Behavior, 10, 1019-1022. https://doi.org/10.1016/0031-9384(73)90182-0

[15] Ortiz-Valladares, M., Torrero, C., Regalado, M. and Salas, M. (2018) Late-Emerging Effects of Perinatal Undernutrition in Neuronal Limbic Structures Underlying the Maternal Response in the Rat. Brain Research, 1700, 31-40. https://doi.org/10.1016/j.brainres.2018.06.033

[16] Jansson, T. and Powell, T.L. (2013) Role of Placental Nutrient Sensing in Developmental Programming. Clinical Obstetrics and Gynecology, 56, 591-601. https://doi.org/10.1097/GRF.0b013e3182993a2e

[17] Rosselet, C., Zennou-Azogui, Y. and Xerri C. (2006) Nursing-Induced Somatosensory Cortex Plasticity: Temporally Decoupled Changes in Neural Receptive Field Properties Are Accompanied by Modifications in Activity-Dependent Protein Expression. Journal of Neuroscience, 26, 10667-10676. https://doi.org/10.1523/JNEUROSCI.3253-06.2006

[18] Lee, A., Clancy, S. and Fleming, A.S. (1999) Mother Rats Bar-Press for Pups: Effects of Lesions of the Mpoa and Limbic Sites on Maternal Behavior and Operant Responding for Pup-Reinforcement. Behavioural Brain Research, 100, 15-31. https://doi.org/10.1016/S0166-4328(98)00109-0

[19] Murmu, M.S., Salomon, S., Biala, Y., Weinstock, M., Braun, K. and Bock J. (2006) Changes of Spine Density and Dendritic Complexity in the Prefrontal Cortex in 
Offspring of Mothers Exposed to Stress during Pregnancy. European Journal of Neuroscience, 24, 1477-1487. https://doi.org/10.1111/j.1460-9568.2006.05024.X

[20] Felix, J., Regalado, M., Torrero, C. and Salas, M. (2014) Retrieval of Pups by Female Rats Undernourished during the Pre- and Neonatal Period. Journal of Behavioral and Brain Science, 4, 325-333. http://dx.doi.org/10.4236/jbbs.2014.47033

[21] Groenewegen, H.J. and Uylings, H.B.M. (2000) The Prefrontal Cortex and the Integration of Sensory, Limbic and Autonomic Information. Progress in Brain Research, 126, 3-28. https://doi.org/10.1016/S0079-6123(00)26003-2

[22] Afonso, V.M., Sison, M., Lovic, V. and Fleming, A.S. (2007) Medial Prefrontal Cortex Lesions in the Female Rat Affect Sexual and Maternal Behavior and Their Sequential Organization. Behavioral Neuroscience, 121, 515-526.

https://doi.org/10.1037/0735-7044.121.3.515

[23] Febo, M., Felix-Ortiz, A.C. and Johnson, T.R. (2010) Inactivation or Inhibition of Neuronal Activity in the Medial Prefrontal Cortex Largely Reduces Pup Retrieval and Grouping in Maternal Rats. Brain Research, 1325, 77-88.

https://doi.org/10.1016/j.brainres.2010.02.027

[24] Torrero, C., Regalado, M., Rubio, L. and Salas, M. (2014) Effects of Neonatal Undernutrition on Development of the Dorsolateral Prefrontal Cortex Pyramidal Cells in the Rat. Journal of Behavioral and Brain Science, 4, 49-57. http://dx.doi.org/10.4236/jbbs.2014.41007

[25] Fleming, A.S. and Rosenblatt, J.S. (1974) Maternal Behavior in the Virgin and Lactating Rat. Journal of Comparative and Physiological Psychology, 86, 957-972. https://doi.org/10.1037/h0036414

[26] Fleming, A.S. and Walsh C. (1994) Neuropsychology of Maternal Behavior in the Rat: C-Fos Expression during Mother-Litter Interactions. Psychoneuroendocrinology, 19, 429-443. https://doi.org/10.1016/0306-4530(94)90030-2

[27] Numan, M. (1994) A Neural Circuitry Analysis of Maternal Behavior in the Rat. Acta Paediatrica, 83, 19-28. https://doi.org/10.1111/j.1651-2227.1994.tb13261.x

[28] Sheehan, T., Paul, M., Amaral, E., Numan, M.J. and Numan, M. (2001) Evidence That the Medial Amygdala Projects to the Anterior/Ventromedial Hypothalamic Nuclei to Inhibit Maternal Behavior in Rats. Neuroscience, 106, 341-356. https://doi.org/10.1016/S0306-4522(01)00286-X

[29] Quirarte, G.L., Roozendaal, B. and Mcgaugh, J.L. (1997) Glucocorticoid Enhancement of Memory Storage Involves Noradrenergic Activation in the Basolateral Amygdala. Proceedings of the National Academy of Sciences United States of America, 94, 14048-14053. https://doi.org/10.1073/pnas.94.25.14048

[30] Numan, M., Bress, J.A., Ranker, L.R., Gary, A.J., DeNicola, A.L., Bettis, J.K. and Knapp, S.E. (2010) The Importance of the Basolateral/Basomedial Amygdala for Goal-Directed Maternal Responses in Postpartum Rats. Behavioural Brain Research, 214, 368-376. https://doi.org/10.1016/j.bbr.2010.06.006

[31] Chavez, C.M., McGaugh, J.L. and Weinberger, N.M. (2013) Activation of the Basolateral Amygdala Induces Long-Term Enhancement of Specific Memory Representations in the Cerebral Cortex. Neurobiology of Learning and Memory, 101, 8-18. https://doi.org/10.1016/j.nlm.2012.12.013

[32] Xiong, H. and Krugers, H.J. (2015) Tuning Hippocampal Synapses by Stress-Hormones: Relevance for Emotional Memory Formation. Brain Research, 1621, 114-120. https://doi.org/10.1016/j.brainres.2015.04.010

[33] National Research Council (2003) Guidelines for the Care and Use of Mammals in Neuroscience and Behavioral Research. The National Academies Press, Washington 
DC. https://doi.org/10.17226/10732

[34] Lynch, A. (1976) Postnatal Undernutrition: An Alternative Method. Developmental Psychobiology, 9, 39-48. https://doi.org/10.1002/dev.420090107

[35] National Research Council (1995) Nutrient Requirements of Laboratory Animals. Fourth Revised Edition, The National Academies Press, Washington DC. https://doi.org/10.17226/4758

[36] Altman, J. and Bayer, S.A. (1995) Atlas of Prenatal Rat Brain Development. CRC Press, Boca de Raton.

[37] Grota, L.J. and Ader, R. (1969) Continuous Recording of Maternal Behaviour in Rattus norvegicus. Animal Behaviour, 17, 722-729. https://doi.org/10.1016/S0003-3472(69)80019-9

[38] Panksepp, J. (1971) Aggression Elicited by Electrical Stimulation of the Hypothalamus in Albino Rats. Physiology \& Behavior, 6, 321-329. https://doi.org/10.1016/0031-9384(71)90163-6

[39] Stern, J.M. (1996) Somatosensation and Maternal Care in Norway Rats. Advances in the Study of Behavior, 25, 243-294. https://doi.org/10.1016/S0065-3454(08)60335-6

[40] Wansaw, M.P., Pereira, M. and Morrell, J.I. (2008) Characterization of Maternal Motivation in the Lactating Rat: Contrasts between Early and Late Postpartum Responses. Hormones and Behavior, 54, 294-301. https://doi.org/10.1016/j.yhbeh.2008.03.005

[41] Sheehan, T.P., Cirrito, J., Numan, M.J. and Numan M. (2000) Using C-Fos Immunocytochemistry to Identify Forebrain Regions That May Inhibit Maternal Behavior in Rats. Behavioral Neuroscience, 114, 337-352. https://doi.org/10.1037/0735-7044.114.2.337

[42] Paxinos, G. and Watson, C. (2006) The Rat Brain in Stereotaxic Coordinates. Sixth Edition, Academic Press, Cambridge.

[43] Jansson, N., Pettersson, J., Haafiz, A., Ericsson, A., Palmberg, I., Tranberg, M., Ganapathy, V., Powell, T.L. and Jansson, T. (2006) Down-Regulation of Placental Transport of Amino Acids Precedes the Development of Intrauterine Growth Restriction in Rats Fed a Low Protein Diet. Journal of Physiology, 576, 935-946. https://doi.org/10.1113/jphysiol.2003.550004

[44] Belkacemi, L., Nelson, D.M., Desai, M. and Ross, M.G. (2010) Maternal Undernutrition Influences Placental-Fetal Development. Biology of Reproduction, 83, 325-331. https://doi.org/10.1095/biolreprod.110.084517

[45] Salas, M., Torrero, C., Regalado, M. and Perez, E. (2002) Retrieving of Pups by Neonatally Stressed Mothers. Nutritional Neuroscience, 5, 399-405.

https://doi.org/10.1080/1028415021000055943

[46] Panksepp, J. and Biven, L. (2012) The Archaeology of Mind: Neuroevolutionary Origins of Human Emotion. W.W. Norton \& Company, New York.

[47] Reisbick, S., Rosenblatt, J.S. and Mayer, A.D. (1975) Decline of Maternal Behavior in the Virgin and Lactating Rat. Journal of Comparative and Physiological Psychology, 89, 722-732. https://doi.org/10.1037/h0077059

[48] Escobar, C. and Salas, M. (1993) Neonatal Undernutrition and Amygdaloid Nuclear Complex Development: An Experimental Study in the Rat. Experimental Neurolo$g y$, 122, 311-318. https://doi.org/10.1006/exnr.1993.1130

[49] Paula-Barbosa, M.M., Tavares, M.A., Borges, M.M. and Gray, E.G. (1984) Presynaptic Inclusions in Mossy Fibre Terminals of the Cerebellar Cortex Following Long-Term Undernutrition in Adult Rats. Journal Neurocytology, 13, 841-847. https://doi.org/10.1007/BF01148588 
[50] Numan, M. (2007) Motivational Systems and the Neural Circuitry of Maternal Behavior in the Rat. Developmental Psychobiology, 49, 12-21.

https://doi.org/10.1002/dev.20198

[51] Walker, S.P., Chang, S.M., Powell, C.A., Simonoff, E. and Grantham-McGregor, S.M. (2006) Effects of Psychosocial Stimulation and Dietary Supplementation in Early Childhood on Psychosocial Functioning in Late Adolescence: Follow-Up of Randomised Controlled Trial. British Medical Journal, 333, 472-476.

https://doi.org/10.1136/bmj.38897.555208.2F

[52] Math, F. and Davrainville, J.L. (1980) Electrophysiological Study on the Postnatal Development of Mitral Cell Activity in the Rat Olfactory Bulb. Influence of Undernutrition. Brain Research, 194, 223-227.

https://doi.org/10.1016/0006-8993(80)91333-5

[53] Tonkiss, J., Galler, J.R., Shukitt-Hale, B. and Rocco, F.J. (1991) Prenatal Protein Malnutrition Impairs Visual Discrimination Learning in Adult Rats. Psychobiology, 19, 247-250.

[54] Córdoba, N.E., Arolfo, M.P., Brioni, J.D. and Orsingher, O.A. (1994) Perinatal Undernutrition Impairs Spatial Learning in Recovered Adult Rats. Acta Physiologica, Pharmacologica et Therapeutica Latinoamericana, 44, 70-76.

http://www.ncbi.nlm.nih.gov/pubmed/7663016

[55] Morgan, H.D., Fleming, A.S. and Stern, J.M. (1992) Somatosensory Control of the Onset and Retention of Maternal Responsiveness in Primiparous Sprague-Dawley rats. Physiology \& Behavior, 51, 549-555. https://doi.org/10.1016/0031-9384(92)90178-5

[56] Regalado, M., Torrero, C. and Salas, M. (1999) Maternal Responsiveness of Neonatally Undernourished and Sensory Stimulated Rats: Rehabilitation of Maternal Behavior. Nutritional Neuroscience, 2, 7-18. https://doi.org/10.1080/1028415X.1999.11747257

[57] Pryce, C.R., Bettschen, D. and Feldon, J. (2001) Comparison of the Effects of Early Handling and Early Deprivation on Maternal Care in the Rat. Developmental Psychobiology, 38, 239-251. https://doi.org/10.1002/dev.1018 